\title{
Drum-Buffer-Rope and Workload Control in High-Variety Flow and Job Shops with Bottlenecks: An Assessment by Simulation
}

\author{
Matthias Thürer, Mark Stevenson, Cristovao Silva and Ting Qu (corresponding author)
}

\author{
Name: $\quad$ Professor Matthias Thürer \\ Institution: Jinan University \\ Address: $\quad$ Institute of Physical Internet \\ School of Electrical and Information Engineering \\ Jinan University (Zhuhai Campus) \\ 519070, Zhuhai, PR China \\ E-mail: $\quad$ matthiasthurer@workloadcontrol.com \\ Name: $\quad$ Professor Mark Stevenson \\ Institution: Lancaster University \\ Address: $\quad$ Department of Management Science \\ Lancaster University Management School \\ Lancaster University \\ LA1 4YX, U.K. \\ E-mail: $\quad$ m.stevenson@lancaster.ac.uk \\ Tel: $\quad 00441524593847$

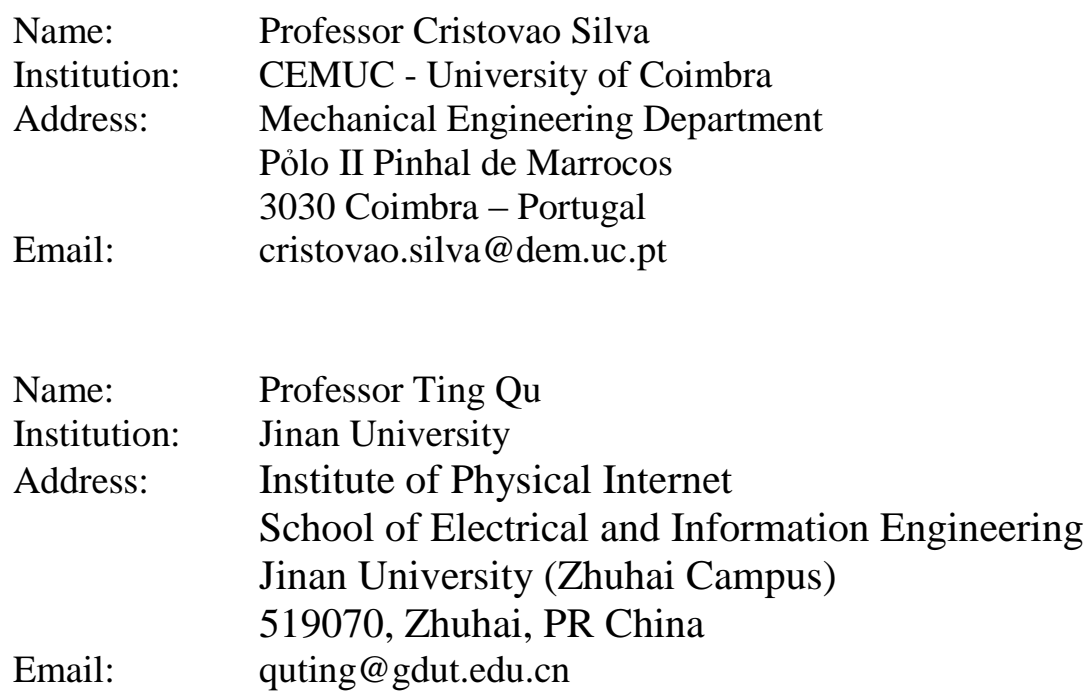

Keywords: Drum-Buffer-Rope; Workload Control; Order Release; Bottleneck; Theory of Constraints. 


\title{
Drum-Buffer-Rope and Workload Control in High-Variety Flow and Job Shops with Bottlenecks: An Assessment by Simulation
}

\begin{abstract}
Two key concepts in the production planning and control literature that incorporate an order release function are the Theory of Constraints, with its drum-buffer-rope release method, and Workload Control, with its load-based release methods. When order release is applied, jobs are not directly released to the shop floor - release is controlled to realize certain performance measures. The performance impacts of drum-buffer-rope and Workload Control order release have been assessed separately, but the two approaches have not been directly compared in one study. This is a major shortcoming that leaves practitioners without guidance on which release method to select. This study assesses the performance of drum-buffer-rope and Workload Control release in a pure job shop and a general flow shop with varying levels of bottleneck severity. Both bottleneck oriented and non-bottleneck oriented Workload Control release methods are included. Simulation results show that Workload Control release methods lead to better performance than drum-buffer-rope if bottleneck severity is low. But Workload Control, including its bottleneck oriented release methods, is outperformed by drum-buffer-rope if a strong (or severe) bottleneck exists. Workload Control gains an advantage in balanced shops due to its unique load balancing function, which attempts to evenly distribute workloads across resources. But this becomes functionless when there is a strong bottleneck. Our sensitivity analysis suggests that the performance differences between release methods are not affected by routing characteristics or the proportion of jobs that visit the bottleneck.
\end{abstract}

Keywords: Drum-Buffer-Rope; Workload Control; Order Release; Bottleneck; Theory of Constraints. 


\section{Introduction}

This study compares the performance of the order release mechanisms contained within the Theory of Constraints (TOC) - i.e. Drum-Buffer-Rope (DBR) - and Workload Control literatures to support managers in their decision concerning which approach to apply in highvariety make-to-order flow and job shops with bottlenecks. The Theory of Constraints originating in the seminal work of Goldratt (e.g. Goldratt \& Cox, 1984, Goldratt, 1990) - is a concept that was specifically designed for shops with bottlenecks. It was originally conceived in the 1970s as a scheduling algorithm and later developed into a broad production planning and control concept (Simons \& Simpson, 1997; Mabin \& Balderstone, 2003). One of its main elements is Optimized Production Technology (OPT), its scheduling (or release) mechanism, that is now more commonly known as Drum-Buffer-Rope (DBR) - a descriptor of the way order release is realized (Simons \& Simpson, 1997). DBR controls (or subordinates) the release of jobs to the system in accordance with the bottleneck (or constraint). The Theory of Constraints can be considered a powerful production planning and control technique in shops with bottlenecks; for example, Mabin \& Balderstone (2003) reviewed the literature on more than 80 successful implementations, with $80 \%$ reporting improvements in lead time and due date performance.

Meanwhile, Workload Control is a production planning and control concept that has been developed over more than 30 years (Thürer et al., 2011). While several different approaches to Workload Control exist, a major unifying element is the use of a load-based order release mechanism. Using the principles of input/output control (Wight, 1970; Plossl \& Wight, 1971), load-based release methods seek to stabilize the workload in the system by releasing work in accordance with the output rate. The Workload Control concept has been shown to significantly improve the performance of high-variety shops both through simulation (e.g. Glassey \& Resende, 1988; Land \& Gaalman, 1998; Thürer et al., 2012, 2014a) and, on occasions, in practice (e.g. Wiendahl, 1992; Bechte 1994; Hendry et al., 2013; Silva et al., 2015). Although Workload Control has been largely developed in the context of balanced shops, there is some evidence of its potential to improve performance in shops with bottlenecks (e.g. Glassey \& Resende, 1988; Lingayat et al., 1995; Enns \& Prongue-Costa, 2002; Fernandes et al., 2014).

In a make-to-order context, both concepts - the Theory of Constraints and Workload Control - use buffers to protect the throughput of the system from variability in the mix of jobs arriving at the shop. Further, both use order release to control the buffers so that buffer costs are 
minimized; if order release is applied, jobs are not released directly to the shop floor on arrival the release of jobs is controlled to create a mix on the shop floor that meets certain performance targets, such as due date adherence and reduced levels of work-in-process. Given their similarities, the two approaches could arguably be used interchangeably or elements of the two approaches combined. In fact, Riezebos et al. (2003) used Workload Control elements to improve DBR. But while there has been a broad literature comparing DBR with Material Requirements Planning (MRP), infinite loading, and kanban systems (see, e.g. Rahman, 1998; Gupta \& Snyder, 2009), to the best of our knowledge, the performance of DBR has not been compared with Workload Control order release. Rather, in the few prior studies that have attempted a comparison, some form of bottleneck oriented Workload Control approach has been used as a proxy for DBR (e.g. Fredendall et al. 2010). This raises the following question: which order release mechanism should be chosen in practice, DBR or Workload Control order release? In response, this study examines the performance of DBR and Workload Control order release in high-variety make-to-order flow and job shops under different levels of bottleneck severity.

The remainder of this paper is structured as follows. In Section 2, we review the literature on DBR and Workload Control in shops with bottlenecks. The simulation model used to evaluate performance is then described in Section 3 before the results are presented, discussed and analyzed in Section 4. Finally, conclusions are drawn in Section 5, where managerial implications and future research directions are also outlined.

\section{Literature Review}

In Section 2.1, we first review the literature on DBR. Section 2.2 then outlines the literature on Workload Control in shops with bottlenecks before an overall assessment of the literature is presented in Section 2.3.

\subsection{Drum-Buffer-Rope (DBR)}

A DBR system is depicted in Figure 1 for a single bottleneck station. Its essential parts can be described as follows:

- Drum: This is the constraint (e.g. the bottleneck station, the market, etc.) and its schedule.

- Buffer: This is both the constraint buffer (i.e. the buffer before the bottleneck) and the shipping buffer (i.e. finished goods inventory; see e.g. Watson et al., 2007). Buffers are time 
(e.g. Radovilsky, 1998; Rahman, 1998; Schragenheim \& Ronen, 1990; Simon \& Simpson, 1997; Chakravorty \& Atwater, 2005) or a time-equivalent amount of work-in-process.

- Rope: This is the communication channel for providing feedback from the drum to the beginning of the system, i.e. order release. Based on this feedback, order release aligns the input of work with the output rate of the bottleneck. In other words, a maximum limit on the number of jobs released to the bottleneck but not yet completed is established and a job is released whenever the number of jobs is below the limit (e.g. Ashcroft, 1989; Lambrecht \& Segaert, 1990; Duclos \& Spencer, 1995; Chakravorty \& Atwater, 1996; Chakravorty, 2001; Watson \& Patti, 2008). There are two ropes: Rope 1 determines the schedule at the bottleneck to exploit the constraint according to the organization's goal (Schragenheim \& Ronen, 1990); Rope 2 then subordinates the system to the constraint (the bottleneck station).

\section{[Take in Figure 1]}

\subsection{Workload Control in Shops with Bottlenecks}

Much of the available literature on Workload Control order release assumes a balanced shop, i.e. with no bottleneck constraint. To the best of our knowledge, the first study to present a bottleneck oriented Workload Control release method was Glassey \& Resende (1988). Glassey \& Resende (1988) proposed a Starvation Avoidance (SA) methodology that essentially releases work whenever the workload queuing or on its way to the bottleneck (but not yet completed) falls below a certain level. This is similar to DBR but controls the workload instead of the number of jobs. Using simulation, Glassey \& Resende (1988) showed that, in job shops, this SA approach outperforms a rule that releases a new job whenever a job is complete. A periodic version of SA (i.e. where the release decision is only taken at periodic time intervals rather than being triggered at any moment in time when starvation occurs) was later shown by Roderick et al. (1992) to be outperformed by Constant Work-in-Process (ConWIP), which also controls the number of jobs in the system, in a shop with restricted routings. It was this periodic version of SA that Fredendall et al. (2010) used as a proxy for DBR. Meanwhile, Lingayat et al. (1995) showed that SA outperforms ConWIP in a job shop, where routings are not restricted. Finally, Enns \& Prongue-Costa (2002) showed that controlling the workload released but not yet completed at the bottleneck resource only, rather than controlling the workload released but not yet completed by the whole shop, leads to better performance in a job shop with a bottleneck 
specifically when bottleneck severity is high. But it was also shown that this approach leads to worse performance in a general flow shop.

The aforementioned studies focused on either controlling the load in the shop as a whole or at the bottleneck. But a major strength of Workload Control is that it can balance workloads across resources, controlling the workload of all stations (Thürer et al., 2012) - if only the workload at the bottleneck is considered, workload balancing cannot be achieved. Fredendall et al. (2010) showed that, in job shops with a bottleneck, controlling the workload at each station (so-called path aggregation) has a beneficial effect on the percentage tardy, lead time, and inventory level compared to bottleneck control and methods that control the total workload in the system. The former method is widely applied in the Workload Control literature (e.g. Bechte, 1994; Oosterman et al., 2000; Cigolini \& Portioli-Staudacher, 2002; Land, 2006; Philipoom \& Steele, 2011). At periodic time intervals, jobs in the pool are considered for release according to a priority value that reflects customer demand, e.g. in terms of due dates. A job contributes to the workload of the station(s) in its routing; and the workload of each station is compared against predetermined workload limits or norms. A job is released if the new workload at each station in the job's routing is below its workload norm; otherwise, the job is retained in the pre-shop pool and the next job in the sequence is considered. A job contributes to the workload of a station until its operation at the station is completed. This method is illustrated in Figure 2.

[Take in Figure 2]

Fredendall et al. (2010) further showed that there are no statistically significant interaction effects between the kind of limit applied (i.e. no limit, a lower limit, or an upper limit) and the difference in utilization levels between bottleneck and non-bottleneck stations (i.e. the bottleneck severity). These findings have recently been extended by Fernandes et al. (2014), who investigated the impact of bottleneck shiftiness on Workload Control in a job shop. The authors' results show that if the utilization at non-bottleneck stations is $5 \%$ less than at the bottleneck station, controlling each station on the shop floor leads to better performance than just controlling the bottleneck station. But if utilization is $20 \%$ less - i.e. a more severe bottleneck exists - then no significant performance differences are observed. However, different from the prior literature, Fernandes et al. (2014) considered the presence of not one but two bottlenecks. As a consequence, bottlenecks could either be adjacent or separated by four non-bottlenecks in 
the routing of a job. While the former is similar to using a single bottleneck, the latter results in quite different shop characteristics that may have influenced the authors' results.

\subsection{Assessment of the Literature}

A broad literature has demonstrated the effectiveness of DBR empirically and theoretically. This literature has compared DBR with MRP (e.g. Duclos \& Spencer, 2001; Steele et al., 2005), infinite loading (e.g. Chakravorty, 2001), and kanban systems (e.g. Lambrecht \& Segaert, 1990; Chakravorty \& Atwater, 1996; Watson \& Patti, 2008); for a review, the reader is referred to Rahman (1998) and Gupta \& Snyder (2009). However, to the best of our knowledge, no study to date has compared the performance of DBR with Workload Control; rather, in the few prior studies that have attempted a comparison, some form of bottleneck oriented Workload Control approach has been used as a proxy for DBR. This makes it difficult for managers in practice to determine which approach to adopt, leading to potential implementation failure. This leads to the following Research Question (RQ):

RQ: How does the performance of Workload Control release compare with Drum-BufferRope in flow and job shops with bottlenecks?

An exploratory study based on controlled simulation experiments will be used to provide an answer to this question. Our focus is hereby on assessing the performance of Workload Control and DBR in a high-variety make-to-order context. In other words, the market is not considered the bottleneck for which throughput needs to be maximized. Rather, on-time delivery is considered the major performance criterion. We will assess the performance impact of Workload Control and DBR for a given level of protective capacity and routing characteristics thereby providing guidance to managers on which order release method to apply. The simulation model and experimental factors used will be outlined next in Section 3.

\section{Simulation Model}

The shop and job characteristics modeled in the simulations are first outlined in Section 3.1. The DBR and Workload Control release methods considered in this study are then outlined in Section 3.2, before the priority dispatching rules applied for controlling the progress of orders on the

shop floor are described in Section 3.3. Finally, the experimental design is outlined and the measures used to evaluate performance are presented in Section 3.4. 


\subsection{Overview of Modeled Shop and Job Characteristics}

Our simulation model has been implemented in the Python ${ }^{\odot}$ programming language using the SimPy ${ }^{\odot}$ simulation module. The modeled shop contains seven stations, where each station is a single, constant capacity resource. As is typical in the literature reviewed in Section 2, each shop has one bottleneck station - in our case, station Number 4. Operation processing times follow a truncated 2-Erlang distribution with a mean of 1 time unit after truncation and a maximum of 4 time units. The inter-arrival time of jobs to the shop follows an exponential distribution with a mean of 0.635 time units, which - based on the probability that the bottleneck station is in the routing of a job (as described below) - deliberately results in a utilization level of $90 \%$ at the bottleneck.

Our focus is on comparing the performance of Workload Control and DBR. Fredendall et al. (2010) highlighted two environmental factors that have a strong impact on performance: bottleneck utilization and the level of protective capacity. In this study, we only consider one utilization level and focus on the latter factor given that it is particular to bottleneck shops. Meanwhile the utilization is relatively high since: a lower utilization would reduce performance differences across rules, and firms are likely to strive for a high utilization of their constraint in practice. As in Enns \& Prongue-Costa (2002) and Fernandes et al. (2014), non-bottlenecks are created by reducing the corresponding processing times. To control for the effect of protective capacity three levels of bottleneck severity are considered: (i) a moderate bottleneck, where processing times at all non-bottlenecks are reduced by 5\%; (ii) a severe bottleneck, where processing times at all non-bottlenecks are reduced by $20 \%$; and, (iii) a very severe bottleneck, where processing times at all non-bottlenecks are reduced by $35 \%$. An equal adjustment was applied to all non-bottlenecks since the position of protective capacity is argued to have no effect on flow times (see Craighead et al., 2001).

Another important environmental factor possibly impacting the performance of Workload Control and DBR is the routing characteristic (Ooosterman et al. 2000). To assess the effect of routing characteristics, two shops are considered as follows:

- The pure job shop (Melnyk \& Ragatz, 1989) or randomly routed job shop (Conway et al., 1967): The routing length of jobs varies uniformly from one to seven operations. The routing length is first determined before the routing sequence is generated randomly without 
replacement; this means re-entrant flows are prohibited (see, e.g. Thürer \& Stevenson (2016) for a discussion on re-entrant flows).

- The general flow shop (Enns, 1995): As above for the pure job shop, but the resulting routing vector (i.e. the sequence in which stations are visited) is sorted such that the routing becomes directed and there are typical upstream and downstream stations.

Finally, due dates are set exogenously by adding a random allowance factor, uniformly distributed between 32 and 40 time units, to the job entry time. The minimum value corresponds to the requirements for the longest routing length ( 7 stations) and the maximum processing time (3.8 time units for non-bottleneck operations and 4 time units for the bottleneck operation) plus an allowance for the waiting or queuing times. The maximum due date allowance of 40 time units was determined through preliminary experiments and set such that, on the one hand, we maintained variability in the due date while, on the other hand, we ensured a certain percentage tardy to avoid incidental effects, as otherwise very few jobs would be responsible for the performance of the shop. Tables 1 summarize the simulated shop and job characteristics.

[Take in Table 1]

\subsection{Order Release}

As in previous simulation studies on Workload Control (e.g. Land \& Gaalman, 1998; Fredendall et al., 2010; Thürer et al., 2012) and DBR (e.g. Lambrecht \& Segaert, 1990; Duclos \& Spencer, 1995; Chakravorty, 2001; Chakravorty \& Atwater, 2005), it is assumed that all jobs are accepted, materials are available, and all necessary information regarding shop floor routings, processing times, etc. is known. Jobs flow into a pre-shop pool to await release according to four alternative release methods - three from the Workload Control literature and DBR.

The four methods are outlined in sections 3.2.1 to 3.2.4 below before Section 3.2.5 describes how the parameters for these methods were set. The first two approaches are taken from the most recent Workload Control literature and have been shown to work well in balanced shops. The last two approaches were developed specifically for shops with bottlenecks.

\subsubsection{LUMS COR}

LUMS COR (Lancaster University Management School Corrected Order Release) was identified as the best solution for Workload Control order release in balanced job shops by Thürer et al. 
(2012). LUMS COR combines a periodic and continuous order release time element. The periodic element keeps the workload $W_{s}^{R}$ released to a station $s$ within a pre-established workload norm. It can be formulated as follows:

(1) All jobs in the set of jobs $J$ in the pre-shop pool are sorted according to their planned release date, given by their due date minus an allowance for the operation throughput time for each operation in their routing.

(2) The job $j \in J$ with the earliest planned release date is considered for release first.

(3) Take $R_{j}$ to be the ordered set of operations in the routing of job $j$. If job $j$ 's processing time $p_{i j}$ at the $i^{\text {th }}$ operation in its routing - corrected for station position $i$ - together with the workload $W_{s}^{R}$ released to station $s$ (corresponding to operation $i$ ) and yet to be completed fits within the workload norm $N_{s}^{C}$ at this station, that is $\frac{p_{i j}}{i}+W_{s}^{R} \leq N_{s}^{C} \forall i \in R_{j}$, then the job is selected for release. That means it is removed from $J$, and its load contribution is included, i.e. $W_{s}^{R}:=W_{s}^{R}+\frac{p_{i j}}{i} \quad \forall i \in R_{j}$.

Otherwise, the job remains in the pool and its processing time does not contribute to the station load.

(4) If the set of jobs $J$ in the pool contains any jobs that have not yet been considered for release, then return to Step 2 and consider the job with the next highest priority. Otherwise, the release procedure is complete and the selected jobs are released to the shop floor.

A released job contributes to $W_{s}^{R}$ until its operation at this station is completed. The load contribution to a station in LUMS COR is calculated by dividing the processing time of the operation at a station by the station's position in the job's routing. Using this "corrected" measure of the aggregate workload (Oosterman et al., 2000) recognizes that a job's contribution to a station's direct load is limited to only the proportion of time that the job is actually queuing and being processed at the station instead of the full time between release and completion at a station.

In addition to the above periodic release mechanism, LUMS COR incorporates a continuous workload trigger. If the load of any station falls to zero, the next job in the pool sequence with that station as the first in its routing is released irrespective of whether this would exceed the 
workload norms of any station. The continuous trigger avoids premature station idleness or starvation (see, e.g. Kanet, 1988; Land \& Gaalman, 1998). When the continuous workload trigger releases a job, its workload contribution to a station is calculated using the same corrected aggregate load approach as used for the periodic release time element of LUMS COR.

\subsubsection{Continuous Release}

Continuous Release (see, e.g. Land et al., 2010; Fernandes \& Carmo-Silva, 2011; Fernandes et al., 2014; Thürer et al., 2014b) is a new breed of release method where a job may be released at any moment in time. This method essentially executes the periodic release element of LUMS COR continuously. In other words, LUMS COR's periodic element is triggered whenever a new job arrives at the shop or an operation is complete (rather than at periodic time intervals).

\subsubsection{Starvation Avoidance COR (SA COR)}

The SA trigger presented in Glassey \& Resende (1988) uses the aggregate of the processing times. Meanwhile, LUMS COR and Continuous Release consider a corrected measure of the processing time. The corrected aggregate load will also be used for SA to make the approach consistent with the other Workload Control release methods considered in this study - with the resulting method referred to as SA COR. SA COR is equivalent to Continuous Release except that it only limits the bottleneck load. As in Enns \& Prongue-Costa (2002), jobs that do not include the bottleneck in their routing - so-called free jobs - are released immediately upon their arrival.

\subsubsection{DBR}

DBR controls the number of jobs released but not yet completed at the bottleneck. Whenever a new job arrives at the shop or an operation is completed at the bottleneck, jobs are released until a pre-established buffer limit is reached. The sequence in which jobs are considered for release is the same as for the three Workload Control release methods described above since the planned release date calculations are similar to the calculations typically applied in DBR (e.g. Simon \& Simpson, 1997; Chakravorty \& Atwater, 2005). As in Chakravorty \& Atwater (2005), and as for SA COR above, jobs that do not include the bottleneck in their routing are released immediately upon arrival. 


\subsubsection{Parameter Setting}

The time interval between releases for the periodic element of LUMS COR is set to 4 time units. The allowance for the operation throughput times used for calculating planned release dates is given by the running average of the actually realized operation throughput times at a station.

Seven workload norm levels (or buffers for DBR) have been considered: from 4 (the maximum possible processing time) to 10 time units for LUMS COR, Continuous Release, and SA COR; and, from 9 to 15 jobs for DBR. These levels are based on preliminary simulation experiments. We did not use different workload norm levels for bottleneck and non-bottleneck stations under LUMS COR and Continuous Release since the performance effects were either not significant or negative in Fernandes et al. (2014). Finally, as a baseline measure, experiments without controlled order release have also been executed, i.e. where jobs are released onto the shop floor immediately upon arrival.

\subsection{Shop Floor Dispatching}

Three dispatching rules are considered for controlling the flow of jobs on the shop floor: (i) the Planned Start Time (PST) rule, a time-based rule that considers the urgency of jobs and is similar to the scheduling mechanism of DBR; (ii) the Shortest Processing Time (SPT) rule, a load-based rule that has been previously shown to reduce throughput times in flow shops (e.g. Conway, 1967); and, (iii) the Modified Planned Start Time (MPST) rule, which combines the SPT and PST rules. The MPST rule is a variant of the Modified Operation Due Date (MODD) rule proposed, e.g. by Baker \& Kanet (1983) and Baker (1984).

The PST rule prioritizes jobs with the earliest planned start time. The planned start time of an operation is determined by successively subtracting an allowance for the operation throughput time for each station in the routing of a job from the job's due date; this is similar to the scheduling mechanism incorporated in DBR (see, e.g. Chakravorty \& Atwater, 2005). The allowance for the operation throughput time is given by the running average of the actually realized operation throughput times at each station. Meanwhile, the SPT rule selects the job with the shortest processing time from the queue. Finally, the MPST rule prioritizes jobs according to the lowest priority number, which is given by the maximum of the earliest planned finish time and earliest possible finish time, i.e. $\max \left(P S T_{i j}+p_{i j}, t+p_{i j}\right)$ for an operation with processing time $p_{i j}$, where $t$ refers to the time when the dispatching decision is made. The MPST rule shifts between a focus on PSTs, to complete jobs on time, and a focus on speeding up jobs - through 
SPT effects - during periods of high load, i.e. when multiple jobs exceed their PST (Land et al., 2015).

\subsection{Experimental Design and Performance Measures}

The experimental factors are: (i) the 7 different norm/buffer levels for our release methods; (ii) the four different release methods (LUMS COR, Continuous Release, SA COR, and DBR); (iii) the three different dispatching rules (PST, SPT, and MPST); (iv) the three levels of bottleneck severity (moderate, severe, and very severe); and, (v) our two shop types (the pure job shop and general flow shop). A full factorial design was used with 504 cells, where each cell was replicated 100 times. Results were collected over 10,000 time units following a warm-up period of 3,000 time units. These parameters are in line with those used in previous studies that applied similar job shop models (e.g. Land, 2006; Thürer et al., 2012) and allow us to obtain stable results while keeping the simulation run time to a reasonable level.

Our focus is on assessing the performance of Workload Control and DBR in a make-to-order context. The on-time delivery of jobs is therefore considered the major performance criterion. The four principal performance measures considered in this study are as follows: the mean throughput time - the mean of the completion date minus the release date across jobs; the mean lead time - the mean of the completion date minus the pool entry date across jobs; the percentage tardy - the percentage of jobs completed after the due date; and, the mean tardiness the conditional lateness, that is $T_{j}=\max \left(0, L_{j}\right)$, with $L_{j}$ being the lateness of job $j$ (i.e. the actual delivery date minus the due date of job $j$ ).

\section{Results}

Statistical analysis has been conducted by applying ANOVA to obtain a first indication of the relative impact of the experimental factors. The ANOVA is here based on a block design with the workload norm (buffer) level as the blocking factor, i.e. the seven workload norm levels (buffers) were treated as different systems. A block design allowed the main effect of the workload norm (buffer) level and both the main and interaction effects of the release methods, dispatching rule, bottleneck severity, and routing characteristics to be captured. Due to space restrictions, we do not present the full results here. All main effects and two and three-way interactions were shown to be statistically significant $(\alpha=0.05)$ except for the two-way interaction 
between routing characteristics and bottleneck severity in terms of the percentage tardy. Meanwhile, significant four-way interactions in terms of the percentage tardy and mean tardiness were observed, with the latter four-way interaction being weak.

The Scheffé multiple-comparison procedure was used to further prove the significance of the differences between the outcomes of the individual release methods and dispatching rules. In addition to using the results of all experiments, we also considered subsets - dividing data according to the level of bottleneck severity. When focusing on the results obtained for all experiments, we found significant differences for all of the rules for most performance measures. Results for the release method, as given in Table 2, suggest that DBR is outperformed by the Workload Control release methods in terms of the percentage tardy but, in terms of mean tardiness, DBR improves performance compared to Continuous Release and SA COR; and performs statistically equivalent when compared to LUMS COR. Meanwhile, results for the dispatching rules, as given in Table 3, show the expected reduction in throughput times for SPT and the improvement in terms of both percentage tardy and mean tardiness for MPST. When comparing the results for different levels of bottleneck severity, we see that, qualitatively, most performance differences are maintained; however, as somewhat expected, the differences between rules diminish with bottleneck severity.

[Take in Table $2 \&$ Table 3]

Detailed performance results are presented next in Section 4.1 for the pure job shop with a moderate bottleneck severity. The impact of an increase in bottleneck severity on performance is then explored in Section 4.2 before the impact of the routing direction is examined in Section 4.3 (general flow shop). Finally, we examine the performance differences between jobs that do and do not visit the bottleneck in Section 4.4.

\subsection{Order Release and Dispatching in a Pure Job Shop with a Moderate Bottleneck}

A major challenge when comparing the performance of different release methods is that the parameters - e.g. workload norms or buffers - are not directly comparable. As a consequence, we had to use a block design for our statistical analysis thereby treating each workload norm (buffer) level as a different system. An approach widely used in the literature that overcomes this shortcoming when comparing release methods is to present results in the form of performance curves. Consequently, our results are presented in the form of performance curves, where the 
left-hand starting point of the curves represents the tightest workload norm level (4 time units) or buffer level for DBR (9 jobs). The workload norm (or buffer) increases step-wise by moving from left to right in each graph, with each data point representing one norm level (from 4 to 10 time units or 9 to 15 jobs). Loosening the norms increases the workload level (in time units of work or number of jobs) and, as a result, increases the throughput times on the shop floor. In addition, and as a reference point, the results obtained when jobs are released immediately are also included. These results are referred to as IMM (IMMediate release) - see single point "X" and represent the outcome with no order release control. This point is located to the right of the curves as it leads to the highest level of work-in-process and, consequently, the longest throughput times on the shop floor.

Figures $3 \mathrm{a}, 3 \mathrm{~b}$, and $3 \mathrm{c}$ show the lead time, percentage tardy and mean tardiness results over the throughput time results obtained for our four release methods in a pure job shop with a moderate bottleneck with PST, SPT and MPST dispatching, respectively.

\section{[Take in Figure 3]}

The following can be observed from the results:

- General Performance: Workload Control order release improves performance compared to immediate release (the single right-hand point in the figures) in terms of all four performance measures considered here. With a moderate bottleneck, release methods that consider bottleneck and non-bottleneck stations (LUMS COR and Continuous Release) outperform release methods that only consider the bottleneck station (SA COR and DBR).

- LUMS COR vs. Continuous: Continuous Release leads to the best performance in terms of the percentage tardy if PST dispatching is applied (Figure 3a). But this is at the cost of mean tardiness, leading to LUMS COR achieving the best mean tardiness performance. Since the lead time is very similar across LUMS COR and Continuous Release, this can be attributed to an increase in the variance of lateness. As expected, SPT significantly reduces the throughput time and reduces performance differences across rules (Figure 3b). As with PST dispatching, the best mean tardiness performance with SPT dispatching is realized by LUMS COR. Finally, LUMS COR is the best-performing release method if MPST dispatching is applied (Figure 3c). 
- DBR vs. SA COR: DBR is either outperformed by SA COR (under PST and SPT dispatching) or leads to equivalent performance (under MPST dispatching) in terms of the percentage tardy. However, DBR outperforms SA COR in terms of the mean tardiness in combination with all three dispatching rules considered. A major difference between SA COR and DBR is that SA COR considers the size of an operation at the bottleneck. This is typically justified by load-balancing considerations. However, since only one station is controlled, balancing considerations are meaningless. Keeping the workload released to the bottleneck station below an upper bound creates some form of SPT sequence, rather than creating a balanced load. Moreover, creating this sequence at release is fairly ineffective since it is planned for a downstream station. As result, compared to DBR, which releases jobs regardless of their workload contribution, SA COR introduces more variance at release, which results in a higher variance of lateness.

- Dispatching: Overall, the best performance is achieved by the release methods with MPST dispatching in terms of the percentage tardy and mean tardiness. MPST improves performance by switching between a focus on PST to produce orders on time and SPT to speed up jobs during periods of high load (Land et al., 2015). This speeding up during highload periods can be observed from the throughput time reduction compared to PST dispatching. Interestingly, lead times increase when throughput times decrease for SPT, while a different relationship can be observed for PST and MPST dispatching. SPT arguably leads to the best lead time performance if no order release is applied, e.g. the lead time and shop floor throughput time are equivalent (see e.g. Conway et al., 1967). Introducing order release leads to a deviation from this sequence since orders are considered for release according to urgency. PST and MPST have a focus on urgency - introducing order release also leads to a sequence deviation, but here it creates load balancing, which reduces lead times.

\subsection{The Impact of Bottleneck Severity on Performance}

Figures $4 \mathrm{a}, 4 \mathrm{~b}$, and $4 \mathrm{c}$ show the lead time, percentage tardy and mean tardiness results over the throughput time results obtained for the four different release methods in a pure job shop with a severe bottleneck, for PST, SPT and MPST dispatching, respectively.

[Take in Figure 4] 
As somewhat expected, if the severity of the bottleneck increases, the performance of SA COR and Continuous Release approach each other since the norm imposed at non-bottleneck stations by Continuous Release is less likely to be violated. However, the main performance differences observed between LUMS COR and Continuous Release in a pure job shop with a moderate bottleneck are maintained. Thus, although SA COR was designed for a bottleneck oriented shop, it is outperformed by LUMS COR when there is a severe bottleneck - this underlines the strength of the LUMS COR approach. Of note is the performance shift for DBR. Although DBR still performs the worst in terms of the percentage tardy under PST dispatching (Figure 4a), it outperforms Continuous Release and SA COR under MPST dispatching. Moreover, it leads to the best mean tardiness performance under MPST. Since the lead time is slightly higher for DBR, this can be attributed to a reduction in the variance of lateness.

A major stronghold of Workload Control order release methods in shops without a fixed bottleneck is their workload balancing capabilities, i.e. their capacity to balance workloads across resources. However, if there is a very severe bottleneck, this capability becomes functionless. Workload Control release methods that focus on workload balancing, such as LUMS COR and Continuous Release, now just create variance at order release without creating the beneficial effect of workload balancing. Therefore, a method such as DBR, which just considers the timing of release (when release is triggered, the most urgent order is released regardless of its load contribution), leads to better performance.

This can also be observed from Figures 5a, 5b, and 5c, which show the lead time, percentage tardy and mean tardiness results over the throughput time results obtained for the four different release methods in a pure job shop with a very severe bottleneck under PST, SPT, and MPST dispatching, respectively.

\section{[Take in Figure 5]}

Three main points can be observed from Figure 5:

- DBR leads to the best performance in terms of the percentage tardy and mean tardiness results if MPST dispatching (our best-performing dispatching rule) is applied (Figure 5c).

- The main performance differences between LUMS COR and Continuous Release are also maintained when the bottleneck becomes very severe. 
- Continuous Release and SA COR achieve equivalent performance, i.e. data points obtained for the two rules largely overlap.

\subsection{The Impact of the Routing Direction on Performance}

Similar conclusions on the relative performance of the release methods to those in the pure job shop can be drawn from our results in the general flow shop, i.e. when routings are directed. This is illustrated by Figures $6 a, 6 b$, and $6 c$, which show the lead time, percentage tardy and mean tardiness results over the throughput time results obtained for the four different release methods in a general flow shop with a severe bottleneck under PST, SPT, and MPST dispatching, respectively. Only the results for one level of bottleneck severity are shown here as the observed effects on release method performance were qualitatively similar across this factor.

\section{[Take in Figure 6]}

The main difference that can be observed by comparing Figure 4, from the pure job shop, with Figure 6 is a slightly larger reduction in the shop floor throughput time at high norm (buffer) levels for the general flow shop. However, this difference in performance between the pure job shop and general flow shop is not specific to the release method and has been identified and explained previously by Thürer et al. (2012).

\subsection{Performance Analysis: Differences between Jobs that Do/Do Not Visit the Bottleneck}

Chakravorty \& Atwater (2005) argued that the percentage of jobs that do not have the bottleneck station in their routing (so-called free goods) have a significant effect on shop performance. However, Chakravorty \& Atwater (2005) modeled different levels of free goods by changing the mix of jobs that arrive at the shop. In this study, we take a different approach since we are interested in the impact of free jobs on the performance differences between release methods. Therefore, we monitor the performance of jobs that have the bottleneck in their routing in isolation and compare this with the overall performance of all jobs (regardless of whether they do or do not have the bottleneck in their routing). We chose to monitor the performance of bottleneck jobs (rather than free jobs) since only these jobs are directly impacted by the release decision of SA COR and DBR.

Figures $7 \mathrm{a}, 7 \mathrm{~b}$, and 7c show the lead time, percentage tardy and mean tardiness results over the throughput time results for bottleneck jobs only for the four different release methods in a 
pure job shop with a severe bottleneck under PST, SPT, and MPST dispatching, respectively. Only results for one level of bottleneck severity and routing direction are shown here as the observed effects on release method performance were qualitatively similar across these factors.

[Take in Figure 7]

When comparing the results in Figure 7 with the results obtained for all jobs in Figure 4, the following can be observed. As expected, bottleneck jobs show a higher throughput time since they include the operation throughput time at the bottleneck. This higher throughput time leads to longer lead times; but the pool waiting time (i.e. the lead time minus the throughput time) does not appear to increase significantly. The longer lead time in turn leads to an increase in the percentage tardy and mean tardiness.

In general, performance differences between release methods and between dispatching rules appear to be hardly affected when comparing the results for all jobs with those for bottleneck jobs only. Thus we extend the results of Chakravorty \& Atwater (2005) - our results suggest that although the main effect of the level of free goods is significant, interaction effects between the mix of bottleneck/non-bottleneck jobs and the control policy (release method and dispatching rule) are of little or no significance. In other words, the right choice of release method and dispatching rule is not affected by the level of free goods.

\section{Conclusions}

Order release is a key function in the Theory of Constraints, in the form of the Drum-BufferRope (DBR) method, and in Workload Control in the form of its various load-based release methods. Yet although the performance effects of DBR and of Workload Control order release have been widely assessed separately, to best of our knowledge, they have never been compared. In response, this study started by asking: how does the performance of Workload Control release compare with Drum-Buffer-Rope in flow and job shops with bottlenecks? Using a simulation model of a Pure Job Shop and of a General Flow Shop with different levels of bottleneck severity (i.e. the difference in average utilization level between bottlenecks and non-bottlenecks), we have shown that Workload Control leads to better performance if bottleneck severity is moderate. However, it is outperformed by DBR if there is a very severe bottleneck. Workload Control, specifically LUMS COR, gains an advantage in shops with moderate bottlenecks via its 
unique load balancing function, which balances workloads across resources. This feature however becomes functionless (and may even become dysfunctional) if there is a severe bottleneck. On the other hand, each time the bottleneck shifts to a different station, the DBR system has to be adjusted, but no changes are required, e.g. for LUMS COR.

Finally, performance differences between release methods are not affected by routing characteristics or the mix of jobs that do or do not visit the bottleneck - which release method to select does not appear to be affected by the percentage of so-called free jobs. Instead, our simulation results show that the major determining factor for choosing a release method in shops with a bottleneck is the severity of the bottleneck.

\subsection{Limitations and Future Research}

A major limitation of our study is that we have only considered one fixed bottleneck. This was motivated by a need to keep the experimental setting to a reasonable level. Future research could assess the impact of multiple bottlenecks and/or shifting bottlenecks (e.g. as in Fernandes et al., 2014) on the performance differences between DBR and Workload Control release methods observed in this study. Future research could also assess performance in a pure flow shop (i.e. where all jobs visit all stations in the same sequence). We did not consider the pure flow shop here since it does not directly compare with the pure job shop or general flow shop in terms of job characteristics. In other words, not only would the routing direction be changed but so too would the number of operations in the routing of an order (in a pure flow shop, each order would have 7 operations whereas, in a pure job shop and a general flow shop, the average number of operations across jobs is 4). Similarly, we only controlled for protective capacity and routing characteristics (pure job shop vs. general flow shop), potentially neglecting other important environmental factors. While this restriction to two major factors is considered to be justified by the need to keep the study to a reasonable level, future research is required to explore the impact of other factors, such as due date tightness, processing time variability, machine failure, rework, and other forms of yield loss.

Meanwhile, our results suggest that if there is a bottleneck then performance is determined by the schedule at the bottleneck rather than, e.g. workload balancing. However, DBR incorporates only a relatively simple schedule based on backward infinite loading; planned release dates for prioritizing jobs at release are calculated based on a constant lead-time offset. Future research could explore how the bottleneck schedule in DBR could be improved without compromising on 
its simplicity. Finally, future research is required to assess the performance impact of the mix of jobs that do and do not have a bottleneck in their routing. Chakravorty \& Atwater (2005) modeled different levels of free goods by changing the mix of orders that arrive at the shop. It could be argued that the significant impact observed by the authors was not due to the change in the level of free goods but due to the change in the mix of jobs that arrive at the shop. Meanwhile, in our study, we focused on the performance differences between free jobs and bottleneck jobs to explore interactions with release method performance. This does not assess the direct performance impact of free goods.

\section{References}

Ashcroft, S.H., 1989, Applying the principles of optimized production technology in a small manufacturing company, Engineering Costs and Production Economics, 17, 79-88.

Baker, K.R., 1984, Sequencing rules and due-date assignments in a job shop, Management Science, 30, 9 , 1093-1104.

Baker, K.R., and Kanet, J.J., 1983, Job shop scheduling with modified operation due-dates, Journal of Operations Management, 4, 1, 11-22.

Bechte, W., 1994, Load-oriented manufacturing control just-in-time production for job shops, Production Planning and Control, 5, 3, 292 - 307.

Bergamaschi, D., Cigolini, R., Perona, M., and Portioli, A., 1997, Order review and release strategies in a job shop environment: A review and a classification, International Journal of Production Research, $35,2,399-420$.

Chakravorty, S.S., 2001, An evaluation of the DBR control mechanism in a job shop environment, OMEGA, 29, 335-342

Chakravorty, S.S., and Atwater, J.B., 1996, A comparative study of line design approaches for serial production systems, International Journal of Operations and Production Management, 16, 6, 91-108.

Chakravorty, S.S., and Atwater, J.B., 2005, The impact of free goods on the performance of drum-bufferrope scheduling systems, International Journal of Production Economics, 95, 347-357.

Cigolini, R., and Portioli-Staudacher, A., 2002, An experimental investigation on workload limiting methods with ORR policies in a job shop environment, Production Planning and Control, 13, 7, 602613.

Conway, R., Maxwell, W.L., and Miller, L.W., 1967, Theory of Scheduling, Reading, MA: AddissonWesley. 
Craighead, C.W., Patterson, J.W., and Fredendall, LD., 2001, Protective capacity positioning: impact on manufacturing cell performance, European Journal of Operational Research, 134, 425-438.

Duclos, L.K., and Spencer, M.S., 1995, The impact of a constraint buffer in a flow shop, International Journal of Production Economics, 42, 175-185.

Enns, S.T., 1995, An integrated system for controlling shop loading and work flow, International Journal of Production Research, 33, 10, 2801-2820.

Enns, S.T., and Prongue Costa, M., 2002, The effectiveness of input control based on aggregate versus bottleneck workloads, Production Planning and Control, 13, 7, 614 - 624.

Fernandes, N.O., and Carmo-Silva, S., 2011, Workload Control under continuous order release, International Journal of Production Economics, 131, 257 - 262.

Fernandes, N.O., Land, M.J., and Carmo-Silva, S., 2014, Workload control in unbalanced job shops, International Journal of Production Research, 52, 3, 679-690.

Fredendall, L.D., Ojha, D., and Patterson, J.W., 2010, Concerning the theory of workload control, European Journal of Operational Research, 201, 1, 99 - 111.

Gardiner, S.C., Blackstone Jr, J.H., and Gardiner, L.R., 1993, Drum-buffer-rope and buffer management study and practices. International Journal of Operations and Production Management, 13, 68-78.

Glassey, C.R., and Resende, M.G., 1988, Closed-loop job release control for VLSI circuit manufacturing, IEEE Transactions on Semiconductor Manufacturing, 1, 36 - 46.

Goldratt, E.M., 1990, What is This Thing Called Theory of Constraints and How Should it be Implemented?, North River Press: New York.

Goldratt, E.M. and Cox, J., 1984, The Goal: Excellence in Manufacturing, North River Press: New York.

Gupta, M., and Snyder, D., 2009, Comparing TOC with MRP and JIT: a literature review, International Journal of Production Research, 47, 13, 3705-3739.

Hendry, L.C., Huang, Y., and Stevenson, M., 2013, Workload control: Successful implementation taking a contingency-based view of production planning \& control, International Journal of Operations and Production Management, 33, 1, 69-103.

Kanet, J.J., 1988, Load-limited order release in job shop scheduling systems, Journal of Operations Management, 7, 3, $44-58$.

Lambrecht, M.R., and Segaert, A., 1990, Buffer stock allocation in serial and assembly type of production lines, International Journal of Operations and Production Management, 10, 2, 47-61.

Land, M.J., 2006, Parameters and sensitivity in workload control, International Journal of Production Economics, 104, 2, $625-638$.

Land, M.J., and Gaalman, G.J.C., 1998, The performance of workload control concepts in job shops: Improving the release method, International Journal of Production Economics, 56-57, 347-364. 
Land, M.J., Su, N.P.B. and Gaalman, G..J.C, 2010, In search of the key to delivery improvement, 16th International Working Seminar on Production Economics, 1st - 5th March, Innsbruck, Austria, Conference Proceedings, 2, 297-308.

Land, M.J., Stevenson, M., Thürer, M., and Gaalman, G.J.C., 2015; Job Shop Control: In Search of the Key to Delivery Improvements, International Journal of Production Economics, 168, 257-266.

Lingayat, S., Mittenthal, J., and O'Keefe, R., 1995, An order release mechanism for a flexible flow system, International Journal of Production Research, 33, 5, 1241-1256.

Mabin, V.J. and Balderstone, S.J., 2003, The performance of the theory of constraints methodology: analysis and discussion of successful TOC applications, International Journal of Operations and Production Management, 23, 568-595.

Melnyk, S.A., and Ragatz, G.L., 1989, Order review/release: research issues and perspectives, International Journal of Production Research, 27, 7, 1081-1096.

Oosterman, B., Land, M.J., and Gaalman, G., 2000, The influence of shop characteristics on workload control, International Journal of Production Economics, 68, 1, 107-119.

Philipoom, P.R. \& Steele, D.C., 2011, Shop floor control when tacit worker knowledge is important, Decision Sciences, 42, 3, 655-688.

Plossl, G.W., and Wight, O.W., 1971, Capacity planning and control, Working paper presented at the APICS International Conference in St.Louis, Missouri.

Radovilsky, Z.D., 1998, A quantitative approach to estimate the size of the time buffer in the theory of constraints, International Journal Production Economics, 55, 113-119.

Rahman, S., 1998, Theory of constraints: a review of the philosophy and its applications, International Journal of Operations and Production Management, 18, 336-355.

Riezebos, J., Korte, G.J., Land, M.J., 2003, Improving a practical DBR buffering approach using workload control, International Journal of Production Research, 41, 4, 699-712.

Roderick, L.M., Phillips, D.T, and Hogg G.L., 1992, A comparison of order release strategies in production control systems, International Journal of Production Research, 30, 3, 611 - 626.

Schragenheim, E. and Ronen, B., 1990, Drum-buffer-rope shop floor control, Production and Inventory Management Journal, 31, 18-22.

Simons, J.V. and Simpson, III, W.P., 1997, An exposition of multiple constraint scheduling as implemented in the goal system (formerly disaster), Production and Operations Management, 6, 3-22.

Silva, C., Stevenson, M., and Thürer, M., 2015, A Case Study of the Successful Implementation of Workload Control: A Practitioner-led Approach, Journal of Manufacturing Technology Management, $26,2,280-296$. 
Steele, D.C., Philipoom, P.R., Malhotra, M.K., and Fry T.D., 2005, Comparisons between drum-bufferrope and material requirements planning: a case study, International Journal of Production Research, $43,15,3181-3208$

Thürer, M., Stevenson, M., and Silva, C., 2011, Three Decades of Workload Control Research: A Systematic Review of the Literature, International Journal of Production Research, 49, 23, 69056935.

Thürer, M., Stevenson, M., Silva, C., Land, M.J., and Fredendall, L.D., 2012, Workload control (WLC) and order release: A lean solution for make-to-order companies, Production \& Operations Management, 21, 5, 939-953.

Thürer, M., Stevenson, M., Silva, C., Land, M.J., Fredendall, L.D., and Melnyk, S.A., 2014a, Lean control for make-to-order companies: Integrating customer enquiry management and order release, Production \& Operations Management, 23, 3, 463-476.

Thürer, M., Qu, T., Stevenson, M., Maschek, T., and Godinho Filho, M., 2014b, Continuous Workload Control Order Release Revisited: An Assessment by Simulation, International Journal of Production Research, 52, 22, 6664-6680.

Thürer, M., and Stevenson, M., 2016, Workload Control in Job Shops with Re-entrant Flows: An Assessment by Simulation, International Journal of Production Research, 54, 17, 5136-5150.

Wahlers, J.L. and Cox, J.F., 1994, Competitive factors and performance measurement: applying the theory of constraints to meet customer needs, International Journal of Production Economics, 37 , 229-240.

Watson, K.J., and Patti, A., 2008, A comparison of JIT and TOC buffering philosophies on system performance with unplanned machine downtime, International Journal of Production Research, 46, 7 , $1869-1885$.

Watson, K.J., Blackstone, J.H., and Gardiner, S.C., 2007, The evolution of a management philosophy: The theory of constraints, Journal of Operations Management, 25, 387-402.

Wiendahl, H.P., Gläßner, J., and Petermann, D., 1992, Application of load-oriented manufacturing control in industry, Production Planning and Control, 3, 2, 118 - 129.

Wight, O., 1970, Input/Output control a real handle on lead time, Production and Inventory Management Journal, 11, 3, 9-31.

Wisner, J. D., 1995, A review of the order release policy research, International Journal of Operations and Production Management, 15, 6, 25 - 40. 
Table 1: Summary of Simulated Shop and Job Characteristics

\begin{tabular}{|c|c|c|}
\hline 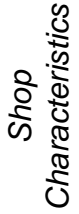 & $\begin{array}{r}\text { Routing Variability } \\
\text { Routing Direction } \\
\text { No. of Stations } \\
\text { Interchange-ability of Stations } \\
\text { Station Capacities }\end{array}$ & $\begin{array}{l}\text { Random routing; no-re-entrant flows } \\
\text { Undirected routing (PJS) and directed routing (GFS) } \\
7 \\
\text { No interchange-ability } \\
\text { All equal }\end{array}$ \\
\hline$\frac{\substack{\frac{0}{0} \\
\frac{.0}{0}}}{\frac{\pi}{0}}$ & $\begin{array}{r}\text { No. of Operations per Job } \\
\text { Operation Processing Times (bottleneck) } \\
\text { Operation Processing Times (non-bottleneck) } \\
\text { Due Date Determination Procedure } \\
\text { Inter-Arrival Times }\end{array}$ & $\begin{array}{l}\text { Discrete Uniform[1, 7] } \\
\text { Truncated 2-Erlang; }(\operatorname{mean}=1 ; \max =4) \\
\text { Truncated 2-Erlang (mean }=1 ; \max =4) \text { times } 0.95 \\
\text { (moderate), } 0.8(\text { severe) and } 0.65(\text { very severe }) \\
\text { Due Date = Entry Time }+d ; d U \sim[32,40] \\
\text { Exp. Distribution; mean }=0.635\end{array}$ \\
\hline
\end{tabular}


Table 2: Results for Scheffé Multiple Comparison Procedure: Release Methods

\begin{tabular}{|c|c|c|c|c|c|c|c|c|c|c|}
\hline & \multirow{2}{*}{$\begin{array}{l}\text { Release } \\
\text { Method (x) }\end{array}$} & \multirow{2}{*}{$\begin{array}{l}\text { Release } \\
\text { Method (y) }\end{array}$} & \multicolumn{2}{|c|}{$\begin{array}{l}\text { Throughput } \\
\text { Time }\end{array}$} & \multicolumn{2}{|c|}{$\begin{array}{l}\text { Lead } \\
\text { Time }\end{array}$} & \multicolumn{2}{|c|}{$\begin{array}{c}\text { Percentage } \\
\text { Tardy }\end{array}$} & \multicolumn{2}{|c|}{$\begin{array}{c}\text { Mean } \\
\text { Tardiness }\end{array}$} \\
\hline & & & lower ${ }^{1)}$ & upper & lower & upper & lower & upper & lower & upper \\
\hline \multirow{6}{*}{$\begin{array}{l}\text { All } \\
\text { Experiments }\end{array}$} & Continuos & LUMS COR & 0.849 & 0.899 & -0.295 & -0.226 & -0.003 & -0.002 & 0.059 & 0.087 \\
\hline & SA COR & LUMS COR & 1.418 & 1.469 & -0.105 & -0.035 & -0.002 & -0.001 & 0.095 & 0.123 \\
\hline & DBR & LUMS COR & 1.009 & 1.060 & 0.274 & 0.343 & 0.007 & 0.008 & $-0.019 *$ & 0.009 \\
\hline & SA COR & Continuous & 0.544 & 0.595 & 0.156 & 0.225 & 0.001 & 0.002 & 0.022 & 0.050 \\
\hline & DBR & Continuous & 0.135 & 0.186 & 0.534 & 0.604 & 0.010 & 0.011 & -0.092 & $\mid-0.064$ \\
\hline & DBR & SA COR & -0.434 & -0.383 & 0.344 & 0.413 & 0.009 & 0.009 & -0.128 & -0.100 \\
\hline \multirow{6}{*}{$\begin{array}{l}\text { Moderate } \\
\text { bottleneck }\end{array}$} & Continuos & LUMS COR & 1.155 & 1.275 & -0.479 & -0.312 & -0.007 & -0.004 & 0.238 & 0.307 \\
\hline & SA COR & LUMS COR & 2.734 & 2.854 & 0.070 & 0.237 & $-0.002 *$ & 0.001 & 0.342 & 0.411 \\
\hline & DBR & LUMS COR & 2.052 & 2.172 & 0.806 & 0.973 & 0.021 & 0.024 & 0.142 & 0.211 \\
\hline & SA COR & Continuous & 1.519 & 1.639 & 0.465 & 0.633 & 0.004 & 0.006 & 0.070 & 0.139 \\
\hline & DBR & Continuous & 0.838 & 0.958 & 1.202 & 1.369 & 0.027 & 0.030 & -0.131 & $\mid-0.062$ \\
\hline & DBR & SA COR & -0.741 & -0.621 & 0.653 & 0.820 & 0.022 & 0.025 & -0.235 & $\mid-0.166$ \\
\hline \multirow{6}{*}{$\begin{array}{l}\text { Severe } \\
\text { bottleneck }\end{array}$} & Continuos & LUMS COR & 0.825 & 0.879 & -0.266 & -0.181 & -0.002 & -0.001 & $-0.028^{*}$ & 0.000 \\
\hline & SA COR & LUMS COR & 0.946 & 1.001 & -0.243 & -0.159 & -0.002 & -0.001 & $-0.024 *$ & 0.003 \\
\hline & DBR & LUMS COR & 0.641 & 0.695 & $-0.006^{*}$ & 0.079 & 0.001 & 0.001 & -0.106 & $\mid-0.078$ \\
\hline & SA CO & Continuous & 0.094 & 0.149 & $-0.020 *$ & 0.065 & $0.000^{*}$ & 0.000 & $-0.010 *$ & 0.017 \\
\hline & DBR & Continuous & -0.211 & -0.157 & 0.218 & 0.302 & 0.002 & 0.003 & -0.092 & $\mid-0.064$ \\
\hline & DBR & SA COR & -0.333 & -0.278 & 0.195 & 0.280 & 0.002 & 0.003 & -0.095 & $\mid-0.068$ \\
\hline \multirow{6}{*}{$\begin{array}{l}\text { Very sever } \\
\text { bottleneck }\end{array}$} & Continuos & LUMS COR & 0.825 & 0.879 & -0.266 & -0.181 & -0.002 & -0.001 & $-0.028 *$ & 0.000 \\
\hline & SA COR & LUMS COR & 0.531 & 0.579 & -0.202 & -0.124 & -0.002 & -0.001 & -0.052 & -0.026 \\
\hline & DBR & LUMS COR & 0.539 & 0.586 & -0.201 & -0.123 & -0.002 & -0.001 & -0.052 & -0.026 \\
\hline & SA COR & Continuous & 0.300 & 0.347 & $-0.040 *$ & 0.038 & $0.000 *$ & 0.000 & -0.112 & -0.086 \\
\hline & DBR & Continuous & $-0.016^{*}$ & 0.031 & $-0.038 *$ & 0.040 & $0.000^{*}$ & 0.000 & $-0.013 *$ & 0.013 \\
\hline & DBR & SA COR & -0.256 & -0.208 & 0.123 & 0.201 & 0.001 & 0.002 & -0.073 & -0.047 \\
\hline
\end{tabular}


Table 3: Results for Scheffé Multiple Comparison Procedure: Dispatching Rules

\begin{tabular}{|c|c|c|c|c|c|c|c|c|c|c|}
\hline & \multirow{2}{*}{$\begin{array}{l}\text { Dispatching } \\
\text { Rule (x) }\end{array}$} & \multirow{2}{*}{$\begin{array}{l}\text { Dispatching } \\
\text { Rule (y) }\end{array}$} & \multicolumn{2}{|c|}{$\begin{array}{c}\text { Throughput } \\
\text { Time }\end{array}$} & \multicolumn{2}{|c|}{$\begin{array}{l}\text { Lead } \\
\text { Time }\end{array}$} & \multicolumn{2}{|c|}{$\begin{array}{c}\text { Percentage } \\
\text { Tardy }\end{array}$} & \multicolumn{2}{|c|}{$\begin{array}{c}\text { Mean } \\
\text { Tardiness }\end{array}$} \\
\hline & & & lower ${ }^{1)}$ & upper & lower & upper & lower & upper & lower & upper \\
\hline \multirow{3}{*}{$\begin{array}{l}\text { All } \\
\text { experiments }\end{array}$} & SPT & PST & -3.462 & -3.424 & -3.973 & -3.921 & 0.000 & 0.001 & 0.386 & \begin{tabular}{|l|}
0.407 \\
\end{tabular} \\
\hline & MPST & PST & -0.171 & -0.133 & -0.298 & -0.246 & -0.015 & -0.014 & -0.072 & -0.050 \\
\hline & MPST & SPT & 3.271 & 3.310 & 3.649 & 3.701 & -0.015 & -0.015 & -0.468 & -0.447 \\
\hline \multirow{3}{*}{$\begin{array}{l}\text { Moderate } \\
\text { bottleneck }\end{array}$} & SPT & PST & -5.739 & -5.648 & -6.722 & -6.596 & -0.011 & \begin{tabular}{|l|}
-0.009 \\
\end{tabular} & 0.544 & 0.596 \\
\hline & MPST & PST & -0.457 & -0.366 & -0.779 & -0.652 & -0.038 & -0.036 & -0.198 & -0.145 \\
\hline & MPST & SPT & 5.236 & 5.327 & 5.880 & 6.007 & -0.028 & -0.026 & -0.768 & -0.715 \\
\hline \multirow{3}{*}{$\begin{array}{l}\text { Severe } \\
\text { bottleneck }\end{array}$} & SPT & PST & -2.749 & \begin{tabular}{|l|}
-2.708 \\
\end{tabular} & -3.062 & -2.998 & 0.006 & \begin{tabular}{|l|}
0.007 \\
\end{tabular} & 0.304 & 0.325 \\
\hline & MPST & PST & -0.049 & -0.008 & -0.094 & -0.030 & -0.004 & -0.003 & $-0.017 *$ & 0.004 \\
\hline & MPST & SPT & 2.679 & 2.721 & 2.936 & 3.000 & -0.010 & -0.010 & -0.332 & -0.311 \\
\hline \multirow{3}{*}{$\begin{array}{l}\text { Very severe } \\
\text { bottleneck }\end{array}$} & SPT & PST & -1.924 & -1.888 & -2.182 & -2.123 & 0.005 & 0.005 & 0.295 & 0.315 \\
\hline & MPST & PST & $-0.034 *$ & 0.002 & -0.068 & -0.009 & -0.003 & -0.002 & $-0.015^{*}$ & 0.005 \\
\hline & MPST & SPT & 1.872 & 1.908 & 2.084 & 2.143 & -0.007 & -0.007 & -0.320 & -0.301 \\
\hline
\end{tabular}




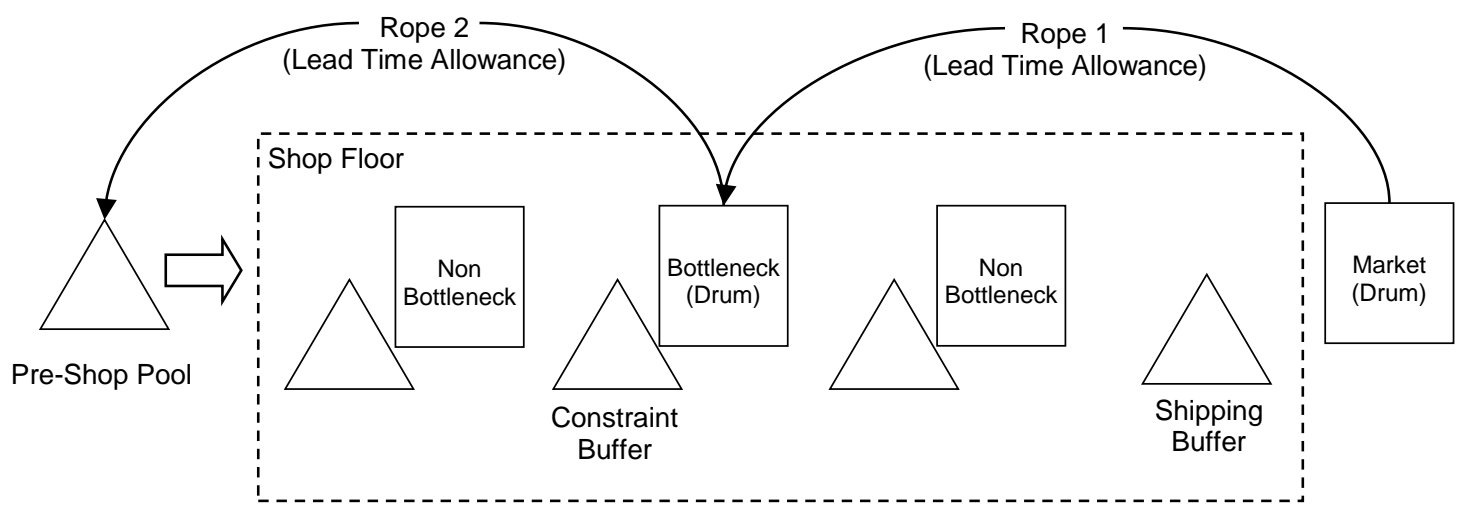

Figure 1: Drum-Buffer-Rope

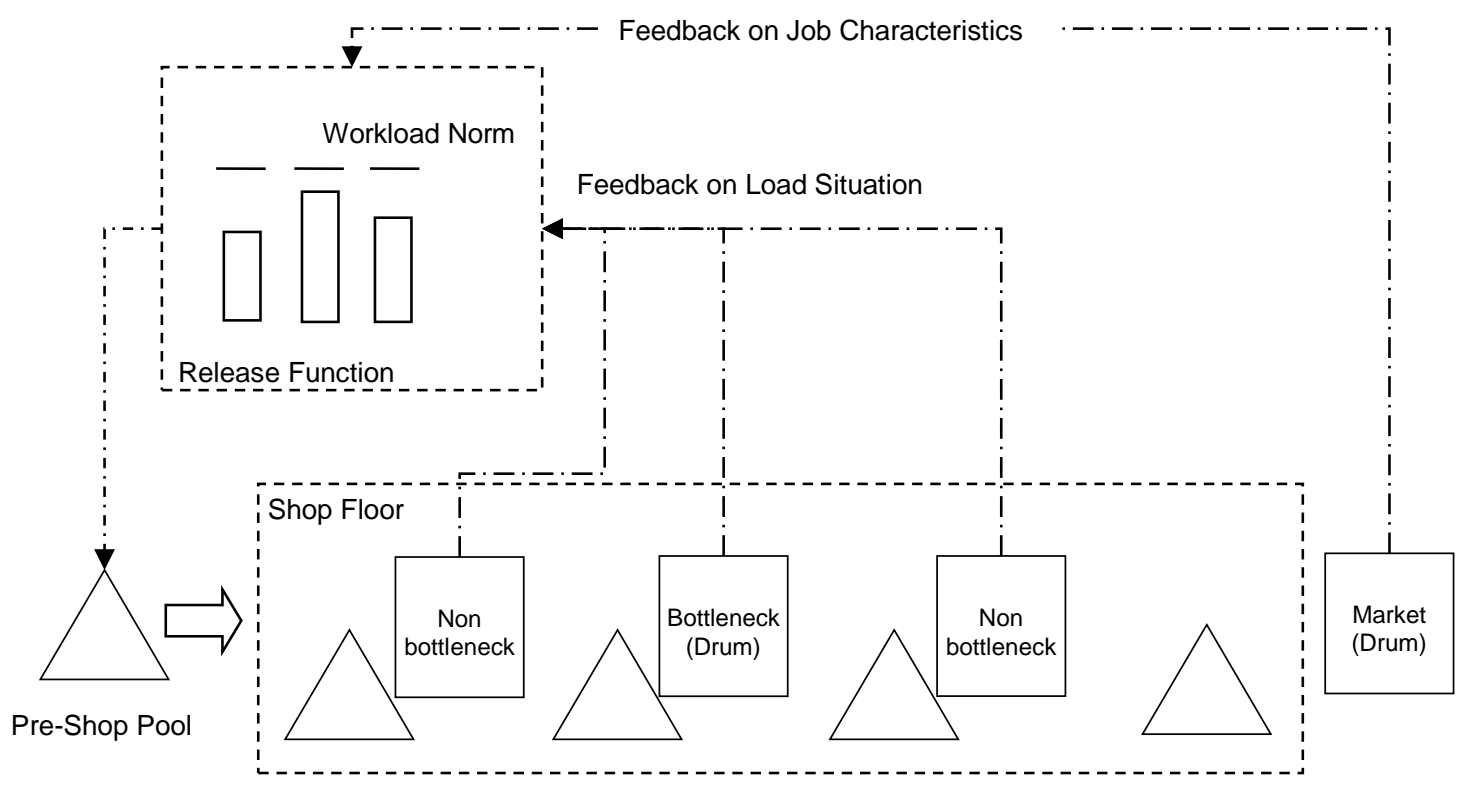

Figure 2: Workload Control - Using a Release Function to Balance the Workload across Resources 

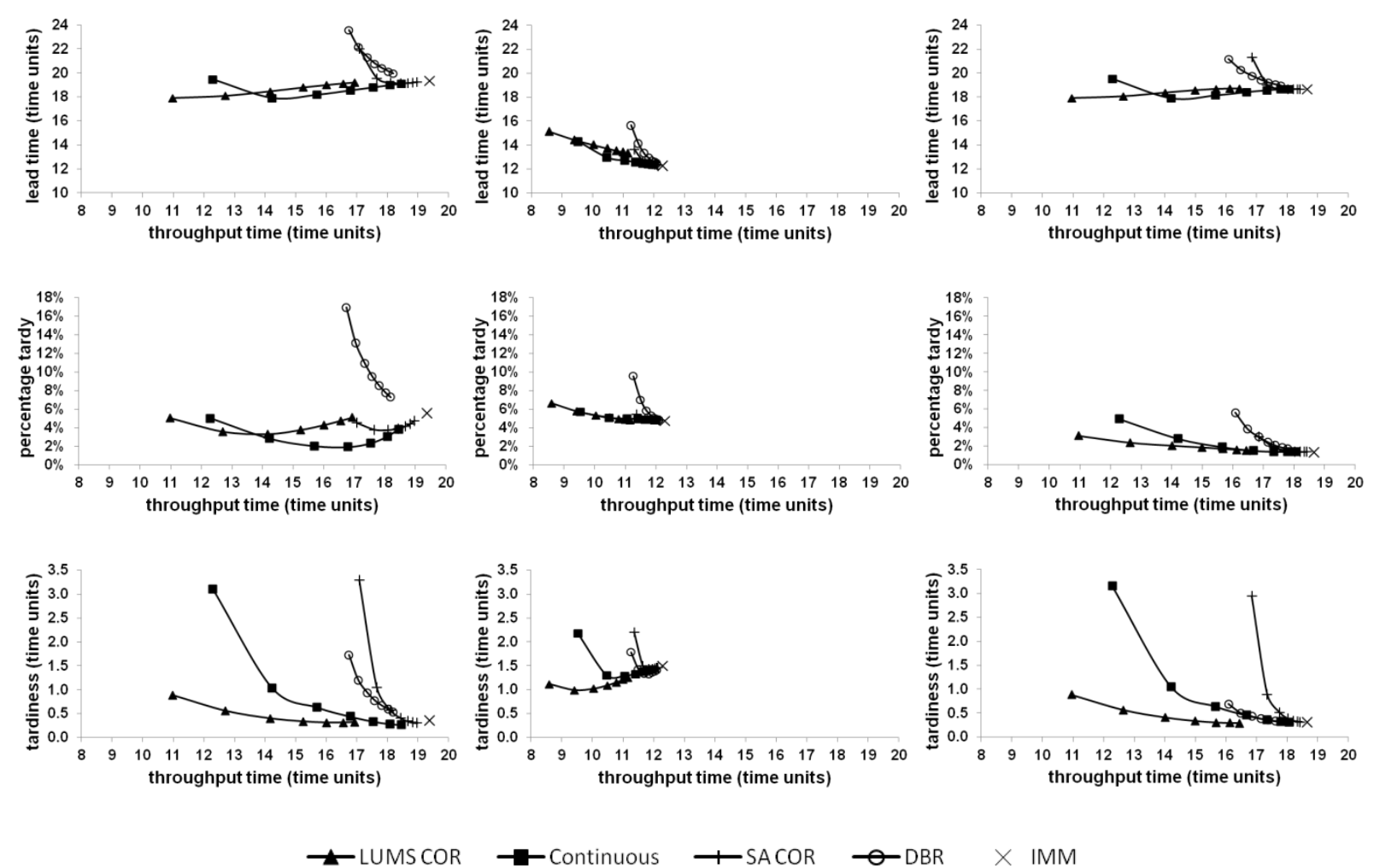

$\rightarrow-$ Continuous

-SACOR $\multimap$ DBR

$\times$ IMM
(a) PST
(b) SPT
(c) MPST

Figure 3: Performance Assessment in a Pure Job Shop with a Moderate Bottleneck and: (a) PST Dispatching; (b) SPT Dispatching; (c) MPST Dispatching 

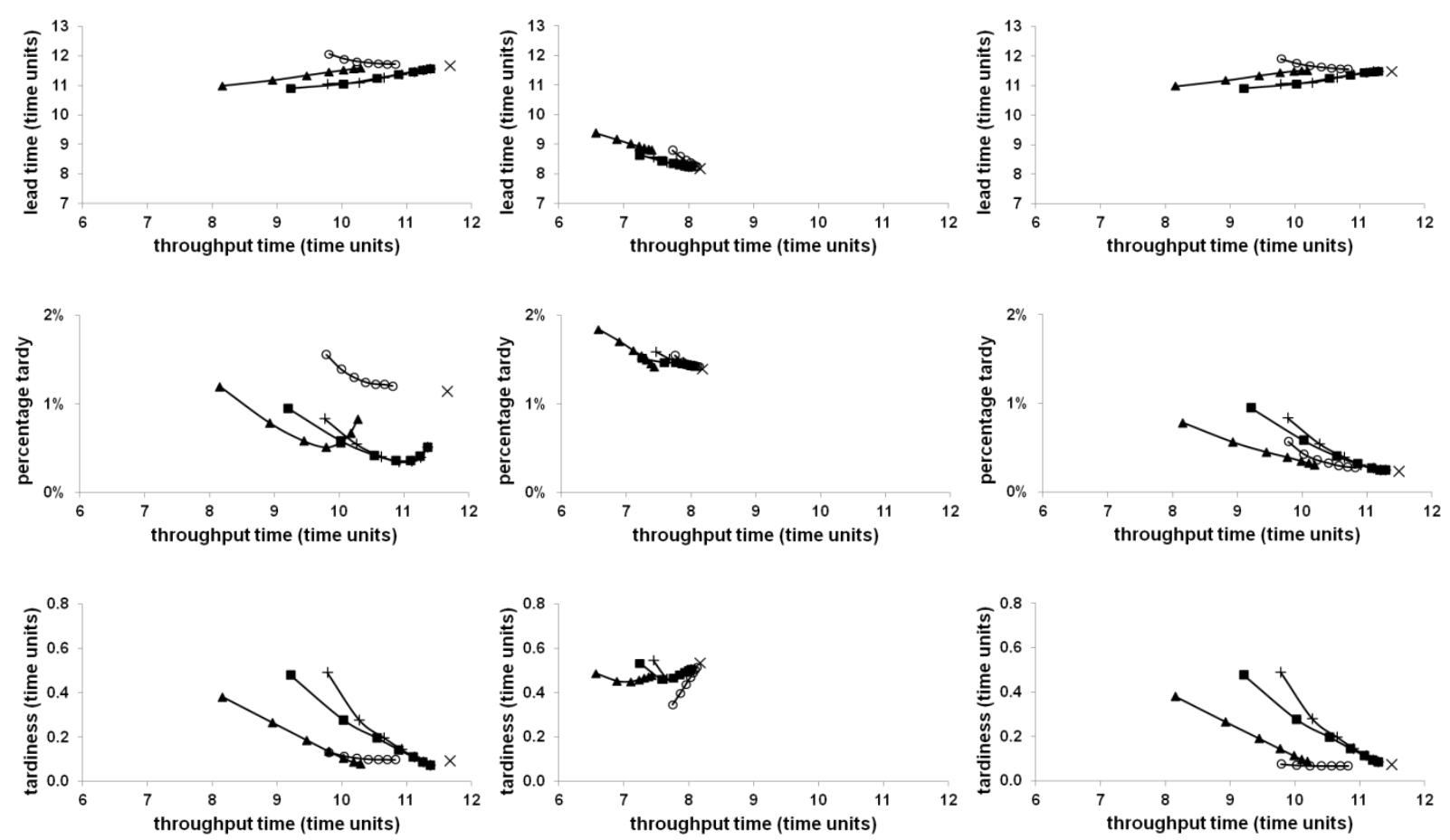

$\neg \leftarrow$ LUMSCOR

$\rightarrow$ Continuous

—SACOR $\quad$-DBR $\times$ IMM
(a) PST
(b) SPT
(c) MPST

Figure 4: Performance Assessment in a Pure Job Shop with a Severe Bottleneck and: (a) PST Dispatching; (b) SPT Dispatching; (c) MPST Dispatching 

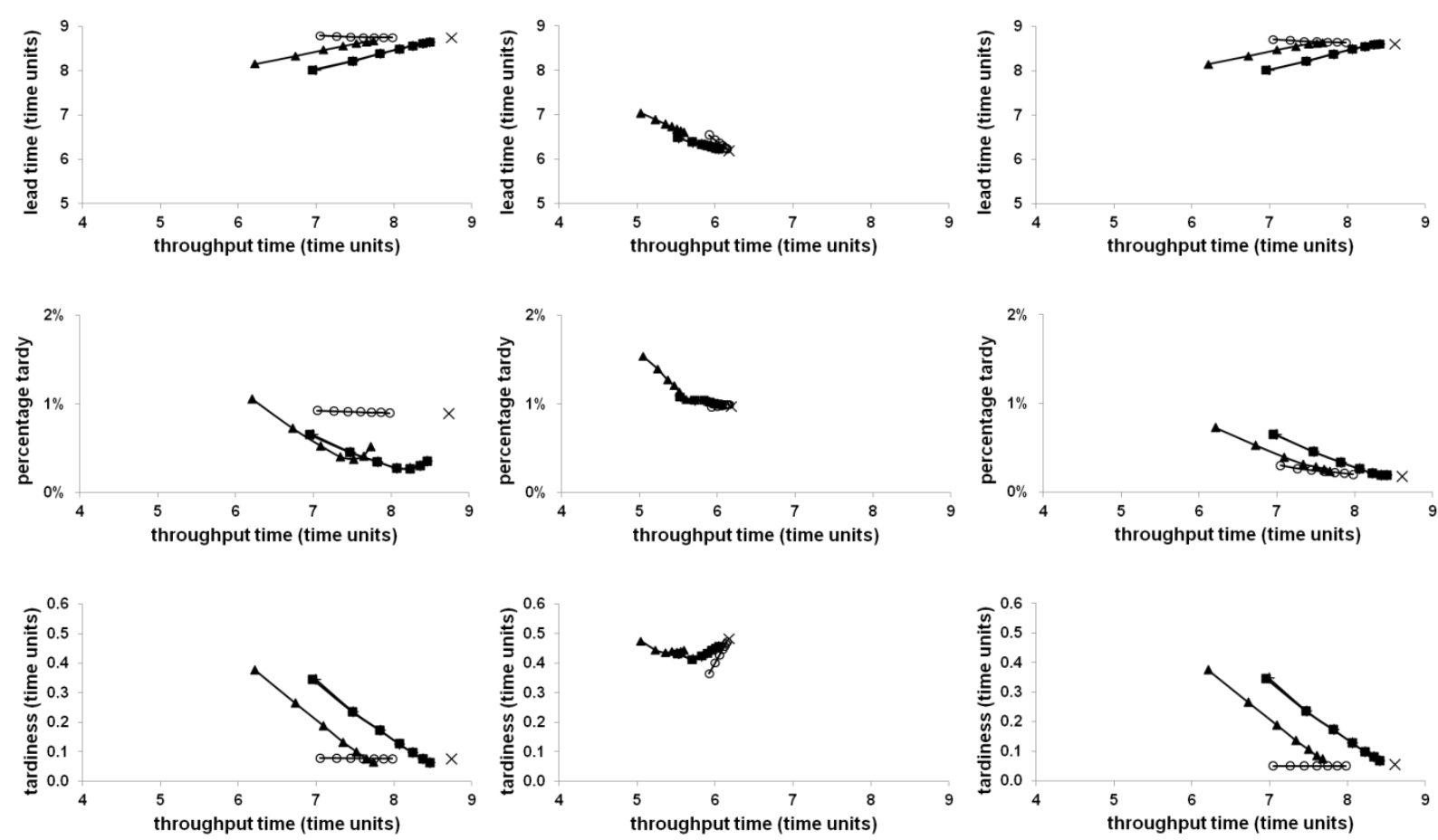

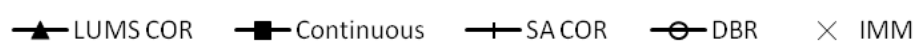
(a) PST
(b) SPT
(c) MPST

Figure 5: Performance Assessment in a Pure Job Shop with a Very Severe Bottleneck and: (a) PST Dispatching; (b) SPT Dispatching; (c) MPST Dispatching 

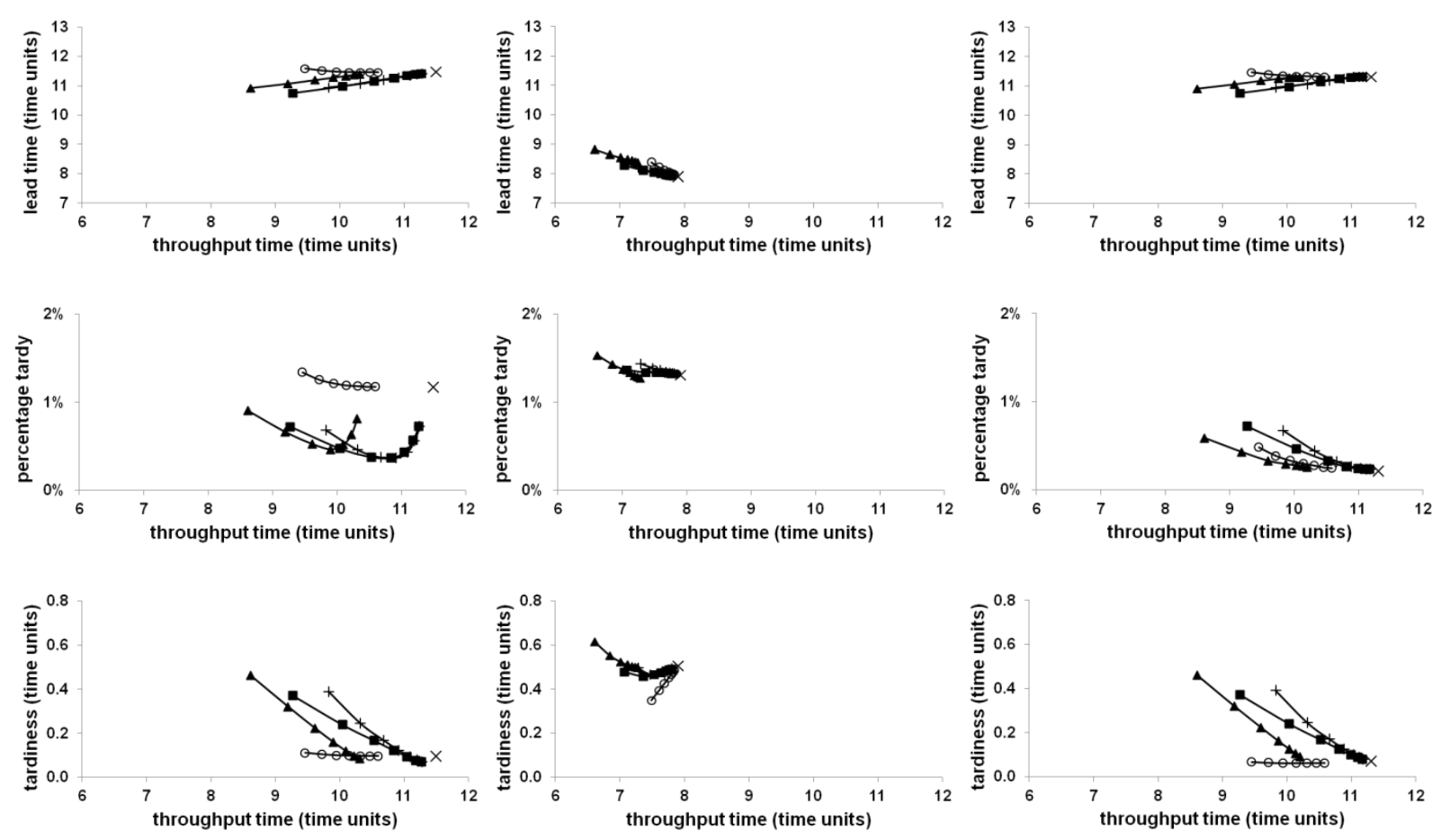

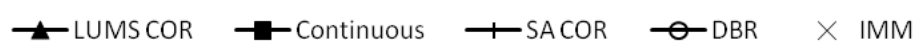
(a) PST
(b) SPT
(c) MPST

Figure 6: Performance Assessment in a General Flow Shop with a Severe Bottleneck and: (a) PST Dispatching; (b) SPT Dispatching; (c) MPST Dispatching 

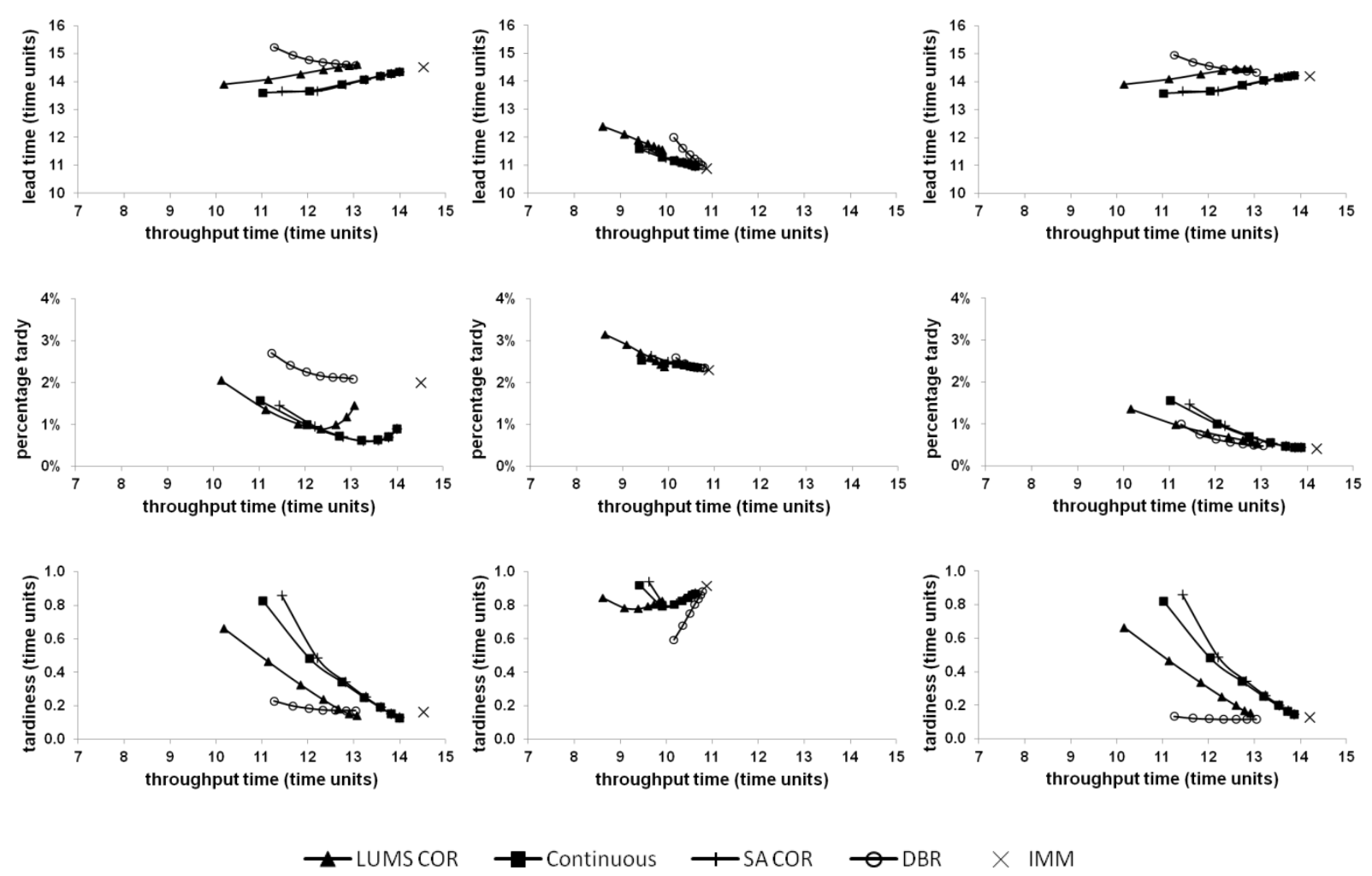

$\rightarrow-$ Continuous

-SACOR $\multimap$ DBR

$\times$ IMM
(a) PST
(b) SPT
(c) MPST

Figure 7: Performance Assessment of Bottleneck Jobs Only in a Pure Job Shop with a Severe Bottleneck and: (a) PST Dispatching; (b) SPT Dispatching; (c) MPST Dispatching 